\title{
ONEROSIDADE EXCESSIVA E CONTRATOS DERIVATIVOS
}

\author{
EXCESSIVE ONEROSITY AND DERIVATIVES
}

Daniel Dela Coleta Eisaqui

\begin{abstract}
Doutorando em Proteção dos Direitos Fundamentais pela Universidade de Itaúna. Mestre em Direitos Difusos e Coletivos pela Universidade Metodista de Piracicaba. Bacharel em Direito pela Universidade Metodista de Piracicaba. Advogado. E-mail: danicoleta@ hotmail.com
\end{abstract}

\section{Victor Hugo Tejerina-Velazquez}

Doutor em Direito Civil pela PUC. Advogado. E-mail: vhtejerina@yahoo.com.br

RESUMO: O presente artigo se propõe a analisar a aplicabilidade da intervenção judicial por onerosidade excessiva nos contratos derivativos. Utiliza-se o método dedutivo, partindo da revisão contratual como fruto do constitucionalismo para concluir que todo o direito privado, inclusive o de mercado de capitais, está sujeito aos direitos humanos que conferem ao direito função de limitador de perda. Assim, a partir da hermenêutica doutrinária quanto aos conceitos de contratos derivativos/aleatórios e quanto à relação entre álea contratual e assunção de riscos pelas partes, estudar-se-á a possibilidade de se revisar ou mesmo resolver contratos derivativos sob o manto da onerosidade excessiva superveniente. Os derivativos assumem cada vez maior relevância com a ampliação do mercado de ações, valores e capitais, de modo que sua suscetibilidade a fatos exógenos à relação subjacente merece acurado estudo, para o fim de encontrar meios profiláticos e saneadores aos efeitos de alteração das circunstâncias, observadas a estabilidade institucional e a segurança jurídica. Desta forma, apesar de o risco ser inerente aos derivativos, a revisão contratual se autoriza quando os níveis de variação excederem o que era possível considerar à época da contratação. Ademais, conclui-se que, em razão da eficácia dos direitos humanos fundamentais sobre o ordenamento jurídico, inclusive o direito privado, que materializa a dignidade humana como limitadora de perdas, a revisão dos contratos deve ser aplicada também aos derivativos.

Palavras-chave: Mercado de Capitais. Derivativos. Contratos Aleatórios. Excessiva Onerosidade. Revisão Judicial.

ABSTRACT: This paper aims to analyze the applicability of judicial review of excessive onerosity to derivatives. It will be used the dedutive approach, assuming that the judicial review of contract is consequence of constitucionalism to conclude that all the private law, including the capital market, is subjet to human rights. Then, the Law has the function to mitigate the loss. In this way, through the doctrinal hermeneutics approach about the concept of derivatives and aleatory contracts, and about the relationship between the contractual risk and the risk taking by the 
contracting parties, will be studied the possibility of review or resolution of derivatives due to subsequent excessive onerosity, The derivatives are increasingly important because of the widening of capital and stock markets, then the changes of circumstances needs to be studied to find out preventive and repairing measures of the effects of changes of circumstances, respecting institutional stability and legal security. Therefore, despite the risk be part of the contract, the judicial review is applicable when the variation levels exceed the foreseeble levels. Furthermore, in conclusion, as effect the effectiveness of human right in the sphere of private law, achieving human dignity as loss limiter, the judicial review of contracts should be applied to derivatives.

Keywords: Capital Markets. Derivatives. Aleatory Contracts. Excessive onerosity. Judicial Review.

SUMÁRIO: Introdução; 1. O revisionismo contratual e a álea dos contratos; 2. Contratos aleatórios; 3. Os derivativos; 4. A onerosidade excessiva nos contratos derivativos; 4.1 A jurisprudência portuguesa; Considerações finais; Referências.

\section{INTRODUÇÃO}

O Direito Privado contemporâneo configura-se como um complexo normativo de inspiração constitucional, de modo que a força normativa da Constituição imprime às relações jurídico-civilistas conformação principiológica afeita aos direitos humanos fundamentais.

Desta forma, o direito privado contemporâneo, para além dos princípios tradicionais, como a pacta sunt servanda e a autonomia da vontade, rege-se subsumido a novos postulados boa-fé, função social, dignidade humana, equilíbrio contratual, eticidade, sociabilidade, operabilidade.

Em decorrência desta nova conformação, não mais se discute o cabimento da intervenção judicial nos contratos, para revê-los quando da superveniência de fatos que alterem a base objetiva do contrato e a equivalência entre as prestações, onerando excessivamente uma - ou mesmo ambas - das partes.

Não obstante a consagração do revisionismo contratual no direito hodierno, subsistem algumas controvérsias acidentais, sendo o propósito deste artigo discorrer sobre o cabimento ou não de revisão dos contratos derivativos sob o manto da teoria da excessiva onerosidade superveniente.

A temática se justifica na medida em que os contratos derivativos são instrumento de proteção aos investidores no mercado de capitais, somado ao fato de que o mercado de ações, valores e capitais vem visualizando um acréscimo do número de investidores ativos.

Ainda, durante a crise econômica de 2007/2008, os tribunais portugueses se viram diante de processos atinentes à aplicação da revisão contratual nos contratos de swap, conforme se estudará no presente trabalho à luz da doutrina de António Menezes Cordeiro, demonstrando que a temática se mostra contemporânea.

O problema da questão surge diante da tese majoritária de que os contratos aleatórios não autorizam a incidência do revisionismo contratual, contraposta a antítese de que os contratos aleatórios podem habilitar a revisão contratual quando os fatos que ensejam o pedido revisional não estão abarcados na álea do contrato, nos riscos assumidos pelas partes.

Através da pesquisa bibliográfica, conceituar-se-á contratos aleatórios, situando os derivativos como subespécie do gênero, a fim de estabelecer um ponto de intersecção entre os requisitos do revisionismo contratual e a álea dos contratos derivativos.

Na primeira parte deste trabalho, é feita uma introdução no que concerne à atuação da álea contratual como limitadora da aplicação da revisão dos contratos. 
Em seguida, estudam-se os contratos aleatórios e a incidência da revisão judicial dos contratos sobre eles. Na terceira parte, introduz-se os derivativos, subespécie de contratos aleatórios existente no mercado de capitais e valores mobiliários.

Após, estuda-se a aplicação da revisão por excessiva onerosidade nos derivativos, a uma, revisando a posição doutrinária e jurisprudencial sobre a matéria, a duas, analisando a jurisprudência portuguesa sobre os swaps após a crise financeira de 2008.

Neste desiderato, são tecidas considerações quanto ao dever de informação como elemento fundacional da decisão de investir, bem como, vinculando o cabimento dos remédios revisionistas ou resolutivos à conjectura informada no momento da contratação.

A título de considerações finais, conclui-se que, como os contratos de mercado de capitais e valores mobiliários são conjecturais e circunstanciais, ou seja, sua conclusão decorre das informações disponíveis à época da pactuação, a superveniência de variações para além do que era possível considerar autoriza a revisão ou resolução dos derivativos.

\section{O REVISIONISMO CONTRATUAL E A ÁLEA DOS CONTRATOS}

Revisão contratual em seu sentido técnico-jurídico, na perspectiva história de sua construção conceitual enquanto instituto do direito privado, pode ser conceituado como o instrumento que as partes contraentes dispõem para solicitar ao juiz que readéque o pacto avençado para eliminar excessiva onerosidade que agrave o cumprimento da prestação, em razão de fatos supervenientes.

Filosoficamente, a revisão contratual é consequência da mudança paradigmática do direito contratual, já que hodiernamente "acima do interesse exclusivamente egoístico, prevalece o interesse social do contrato, sua interação e potenciais reflexos para toda a comunidade" (SAMPAIO; FERREIRA, 2014, p. 152).

Trata-se, com efeito, de consequência do valor ético da funcionalização social do contrato, de matiz constitucional, haja vista o fato de o constitucionalismo erigir a Fraternidade como paradigma axiológico das relações privadas, concretizando-se na licitude e no equilíbrio do exercício do direito regular e da liberdade de contratar (SAMPARIO; FERREIRA, 2014, p. 152).

O Constitucionalismo é, pois, a ótica racional-sistemática que erige a Constituição como ápice da ordem jurídica e substrato da legitimidade do direito, cujo conteúdo consiste na aplicabilidade de direitos fundamentais no âmbito privado (IRIBURE JUNIOR; GUIMARÃES, 2017, p. 126).

Nesta esteira, como "a lei suprema reconheceu as carências e particularidades dos indivíduos, conferindo proteção específica àqueles socialmente mais vulneráveis" (IRIBURE JUNIOR; GUIMARÃES, 2017, p. 130), a revisão contratual tem caráter eminentemente constitucional.

A revisão contratual, em sua evolução histórico-geográfica, conformou-se de diversas maneiras - a Imprevisão, na França (CUNHA, 2007, p. 183); a Excessiva Onerosidade, na Itália (DIAS, 2017, p. 40), a Base do Negócio, na Alemanha (CUNHA, 2007, p. 185), a Alteração das Circunstâncias, em Portugal (CORDEIRO, 2017, p. 549).

Não obstante essas teorias prima-irmãs terem suas particularidades, cada qual dando relevo a um viés do revisionismo contratual, todas elas, no entanto, estão sustentadas na comutatividade do negócio jurídico (GONÇALVES, 2014, p. 51), bem como na exigência da superação da álea comum dos contratos (ROPPO, 2009, p. 262).

Nesta senda, pois, via de regra, o contrato do qual se requer a revisão ou resolução "não poderá ser aleatório, porque o risco é de sua própria natureza, e, em regra, uma só das partes assume deveres" (DINIZ, 2014, p. 184).

A bem da verdade, todo contrato contém risco, sendo a álea elemento inerente à operação econômica do contrato, de modo que "a mera conclusão de um contrato é uma exposição ao risco" 
(CURY, 2014, p. 92 e p. 95), de modo que, como observara Pontes de Miranda (2001, p. 102), "Bons negócios de hoje podem tornar-se, no futuro, maus negócios."

Por esta razão, então, aquele que contrata "não pode deixar de questionar até que ponto participar do contrato é compensador a ela" (CURY, 2014, p. 96), o que implica dizer, que os contraentes devem analisar quais riscos estão dispostos a assumir:

Desta forma, as partes podem optar por dilatar a álea normal do contrato, gerando uma álea convencionada, de caráter qualitativo igual ao da álea normal, porém quantitativamente maior. Tal alongamento se dá na assunção, por uma das partes, de um risco específico, ligado à possibilidade de execução da sua prestação ou mesmo a um elemento da situação contratual, mas não a um risco alheio à causa do contrato (por isso não tem caráter qualitativo). (CURY, 2014, p. 98)

Esta alteração convencional da álea contratual, contudo, não torna um contrato comutativo em contrato aleatório, mas modifica o limite da aplicação da onerosidade excessiva (CURY, 2014, p. 99).

Neste sentido, por exemplo, os contratos agrícolas de entrega futura de soja se sujeitam ao risco da perda da safra em razão de intempéries climáticas, conforme decidido pelo Tribunal de Justiça do Estado de São Paulo na Apelação no 0002926-57.2015.8.26.0218, rel. Kioitsi Chicuta, 32a Câmara de Direito Privado, j. 10.08.2017: secas e chuvas integram a álea normal de um contrato futuro agrícola. No entanto, podem as partes convencionar o alargamento da álea contratual para incluir o aumento do preço dos insumos necessários à produção.

Considere-se um produtor de soja que avençou a entrega de uma quantidade 20.000 sacas de soja durante a safra 2018. Sobreveio um aumento excessivo no preço dos insumos necessários à produção da soja, de modo que ele só conseguiria produzir metade da safra no prazo pactuado.

Neste cenário poderia ele pleitear a revisão contratual para (a) entregar 20.000 sacas de soja nas duas próximas safras - 10.000 sacas em 2018, 10.000 sacas em 2019 - ou seja, uma alteração na forma de entrega, transformando a prestação instantânea em sucessiva/parcelada; (b) reduzir sua prestação, implementado sua obrigação contratual com a entrega de tão somente 10.000 sacas durante a safra original de 2018; (c) resolver o contrato, na hipótese de não ser interessante à contraparte a revisão do pacto com a redução da quantidade ou dilatação do prazo de entrega.

No entanto, caso as partes tenham incluído o risco do aumento dos insumos na álea do contrato, duas situações aparecem. A uma, verificar se o aumento extrapolou o aumento assumido pelas partes, o que autorizaria a revisão ou resolução por excessiva onerosidade; a duas, caso o aumento tenha sido razoável e dentro dos limites que as partes teriam abarcado no contrato, a avença permanece hígida.

Da parte do comprador da soja, igualmente, a variação do preço da saca da soja constitui risco ínsito ao negócio jurídico, como assentou o Tribunal de Justiça do Rio Grande do Sul ao julgar a Apelação n ${ }^{\circ}$ 70020068730, rel. Iris Helena Medeiros Nogueira, 9a Câmara Cível, j. 08.08.2007. Quando a parte assume a compra de saca a preço futuro, está-se diante de um risco tipicamente conexo com as operações e andamentos médios do mercado agrícola em que está inserido (CURY, 2014, p. 99).

Essas situações apresentadas exemplificam que a revisão contratual exige que o negócio jurídico tenha um regulamento completo, ou seja, que os elementos de riscos assumidos estejam bem definidos:

Logo, o desequilíbrio permitido nos aleatórios é tão somente aquele causado pelo fato futuro expressamente previsto. (...) as partes, ao estipular um contrato aleatório, assumem unicamente a álea própria do contrato, de forma que os desequilíbrios supervenientes não relacionados a ela recebem a mesma disciplina prevista para os contratos comutativos. (...) para os fatos excluídos da álea típica 
dos aleatórios, o regime dos comutativos referente à onerosidade excessiva (...) é plenamente aplicável (CARDOSO, 2010, p. 161).

Com estas considerações, pode-se concluir que a revisão contratual não se conforma a padrões abstratos, mas exige a análise das particularidades do caso concreto.

As categorias que servem de requisitos à aplicação das teorias revisionistas são pontos de partida e balizas para o aplicador do Direito, mas não são estanques - a normatização estrutura o instituto jurídico, mas os limites de sua aplicação estão adstritos à espécie fática.

\section{CONTRATOS ALEATÓRIOS}

Contrato aleatório é aquele que, não obstante bilateral e oneroso, é caracterizado pela incerteza, pelo fato de que as vantagem e sacrifícios, perdas ou lucros, dependem de fato futuro e imprevisível (GONÇALVES, 2014, p. 97).

Sua denominação decorre do vocábulo latino alea, cujo significado é justamente sorte, risco, azar, denotando dependência do acaso ou do destino (GONÇALVES, 2014, p. 157).

Nestes contratos, perfeitos e eficazes desde a sua conclusão, o que surge é o "risco de a prestação de uma das partes ser maior ou menor, ou mesmo não ser nenhuma", de modo que a declaração de vontade nos contratos aleatórios consubstancia a assunção consciente desta probabilidade de prestações desproporcionais (GONÇALVES, 2014, pp. 158-159).

O que se dá nos contratos aleatórios, pois, é a questão de se haverá ganho ou perda, e não quanto se ganhará, quanto a prestação de uma parte equivale à contraprestação (CARDOSO, 2010, p. 158).

Há de se frisar, porém, que a álea estará presente "sempre que haja atribuições patrimoniais de valores certos, mas que não haja simultaneidade entre o momento de conclusão e o de execução do contrato", de modo que este decurso temporal pode acarretar variações aos custos das prestações (CARDOSO, 2010, p. 159).

No que concerne à incidência da revisão contratual sobre os contratos aleatórios, a alegação de desequilíbrio e a aplicação do remédio jurídico é dependente da "previsibilidade do evento causador do desequilíbrio", já que "uma gama de eventos supervenientes é abstratamente prevista, de modo que ainda que não se preveja qual o evento em si causador do desequilíbrio, a possibilidade dele ocorrer constitui a razão de ser desses contratos" (CARDOSO, 2010, p. 162).

Assim, não resta inaplicável a onerosidade excessiva aos contratos aleatórios, conforme exemplifica José de Oliveira Ascensão citado por Luiz Philipe Tavares de Azevedo Cardoso: os riscos de quem aposta na Bolsa de Valores concerne à oscilação das cotações, mas o enceramento das Bolsas é ocorrência extraordinária que autoriza a revisão ou resolução do contrato (CARDOSO, 2010, p. 162).

Em síntese, admite-se "a aplicação do instituto da onerosidade excessiva nas situações em que o evento extraordinário e imprevisível não tenha relação com o risco implícito da estrutura contratual" (CURY, 2014, p. 101), conforme enunciados das Jornadas de Direito Civil ${ }^{1}$ e das Jornadas de Direito Comercial. ${ }^{2}$

\footnotetext{
${ }^{1}$ Enunciado 366 da IV Jornada de Direito Civil: "O fato extraordinário e imprevisível causador de onerosidade excessiva é aquele que não está coberto objetivamente pelos riscos próprios da contratação" e o Enunciado 440 da $\mathrm{V}$ Jornada de Direito Civil: "É possível a revisão ou resolução por excessiva onerosidade em contratos aleatórios, desde que o evento superveniente, extraordinário e imprevisível não se relacione com a álea assumida no contrato."

${ }^{2}$ Enunciado 25 da I Jornada de Direito Comercial: "A revisão do contrato por onerosidade excessiva fundada no Código Civil deve (...) observar a alocação de riscos (...)". Trata-se de redação idêntica ao do enunciado 439 da V Jornada de Direito Civil.
} 


\section{OS DERIVATIVOS}

Em termos conceituais, derivativos são instrumentos financeiros cujo valor depende ou deriva do valor de outro, sendo dependentes de qualquer variável, desde o preço da arroba suína até a quantidade de neve que cai em determinado resort de esqui (HULL, 2003, p. 1).

Quanto à sua natureza jurídica, os derivativos são contratos bilaterais, sinalagmáticos, diferenciais, aleatórios, no mais das vezes atípicos, a prazo, consensual, sem formato rígido, não real e patrimonial (MAFUD, 2014, pp. 84-85).

Os mais simples dos derivativos são os contratos a termo (forward contracts), que vem a ser um acordo de compra e venda de um ativo em um momento futuro por um determinado preço - uma parte concorda em comprar o ativo em uma data e por um preço específicos, e a contraparte concorda em vende-lo na mesma data e pelo mesmo preço (HULL, 2003, p. 2).

Assemelhado aos contratos a termo, existem os contratos futuros, diferindo pelo fato de não possuírem uma data especificada (HULL, 2003, p. 6).

A partir desses exemplos sobre essas espécies de derivativos, pode-se concluir que um elemento essencial aos derivativos é o tempo - "um derivativo representa um contrato que é fechado em uma data inicial, mas que tem um prazo determinado para que suas cláusulas sejam honradas" (CLIMENI; KIMURA, 2008, pp. 4-5).

Um segundo elemento caracterizador dos derivativos são os riscos (CLIMENI; KIMURA, 2008, pp. 5-6), já que o "dinamismo do mercado implica diversos e complexos cenários futuros possíveis", gerando incerteza sobre quais mudanças ocorrerão e como atuarão os efeitos decorrentes das alterações (CLIMENI; KIMURA, 2008, p. 60).

A globalização, que ocasionou uma aproximação sem precedentes entre os países e aumentou a velocidade das comunicações (SILVA, 2008, p. 27), implicou em um "aumento das transações e fluxos financeiros entre países", bem como ampliou os riscos aos quais um negócio se sujeita (CLIMENI; KIMURA, 2008, p. 61).

Desta sorte, "eliminar todos os riscos é uma tarefa quase impossível dentro de um panorama financeiro tão globalizado e em um ambiente em que as incertezas e fontes de risco são inúmeras" (CLIMENI; KIMURA, 2008, p. 63).

Assim sendo, os negócios jurídicos abarcam riscos intrínsecos a natureza negocial e, porquanto disso, são assumidos pelos negociantes (CLIMENI; KIMURA, 2008, p. 64).

Neste diapasão, pois, a aplicação da onerosidade excessiva perpassa pela análise de quais riscos foram abarcados pela negociação e qual a natureza dos acontecimentos supervenientes, na esteira da doutrina atinente à matéria em relação aos contratos aleatórios.

\section{A ONEROSIDADE EXCESSIVA NOS CONTRATOS DERIVATIVOS}

Analisando a doutrina e jurisprudência atinente ao tema, encontra-se posição majoritária, porém não pacífica, no sentido da inaplicabilidade dos remédios revisionistas aos derivativos, conforme expõe-se síntese da revisão bibliográfica que segue.

O enunciado 35 da I Jornada de Direito Comercial asseverou que "Não haverá revisão ou resolução dos contratos de derivativos por imprevisibilidade e onerosidade excessiva (arts. $317 \mathrm{e}$ 478 a 480 do Código Civil)."

Sobre a matéria manifestou-se o Tribunal de Justiça do Estado de São Paulo, na Apelação $n^{\circ}$ 0105673-27.2010.8.26.0100, rel. Francisco Loureiro, 37 ${ }^{\mathrm{a}}$ Câmara de Direito Privado, j. 24.11.2011, consignando ser inaplicável "a teoria da imprevisão, ou onerosidade excessiva dos artigos 478 e 481 do Código Civil, e muito menos a teoria da quebra da base do negócio jurídico do art. $6^{\circ}$ do Código de Defesa do Consumidor", argumentando que 
(...) o contrato celebrado entre as partes é de natureza aleatória. [...] a álea, a aposta inversa que fizeram as partes, era exatamente a maior ou a menor variação do câmbio. (...) a realidade é que desequilíbrios econômicos, locais ou mundiais constituíam a própria essência da aposta em que se envolveram as partes.

Ary Oswaldo Mattos Filho (2015, p. 241), explica que

(...) os contratos derivados se caracterizam pela alia, pela incerteza do futuro, gerando a imprevisibilidade quanto ao resultado do evento ou termo final do contrato, face a variáveis climáticas, econômicas ou políticas. (...) a incerteza no amanhã é ínsita a tais contratos. Desta feita, não será qualquer imprevisibilidade que dará margem à dissolução do vínculo. Se as alterações de valor são características do próprio mercado, não há que se falar em imprevisibilidade do negócio feito. As variações cambiais, da taxa de juros, de ações ou do mercado de commodities agrícolas ou minerais fazem parte do próprio negócio derivado, não sendo causa para resolução da obrigação contratual.

Rafael Gaspar dos Santos (2017, pp. 74-75), fundamentou seu trabalho de conclusão dos cursos de LLM de Direito dos Mercados Financeiro e de Capitais e LLM de Direito dos Contratos do Instituto de Ensino e Pesquisa [INSPER], sobre a ideia da inaplicabilidade da teoria da imprevisão aos derivativos, argumentando que "o risco, a álea, integra a própria causa de contratar nessa modalidade de contratação", de modo que "a álea extraordinária nos contratos de derivativos seria algo extremamente difícil de ocorrer na prática."

Daniel Sivieri Arruda (2010, pp. 281-282), em obra monográfica produzida junto à Escola de Direito do Rio de Janeiro da Fundação Getúlio Vargas e vencedora do X Concurso de Monografias CVM e BM\&FBOVESPA, cujo enfoque foi a inaplicabilidade da teoria da imprevisão aos derivativos, sustenta sua posição obtemperando que a pactuação desta espécie de contrato perpassa pelo conhecimento das partes quanto aos riscos presentes e consequências de mudanças no mercado financeiro:

(...) não há como se argumentar que uma variação monetária, ou qualquer outro acontecimento, seja considerado um evento imprevisível. No mundo globalizado de hoje nada pode ser considerado imprevisível ou extraordinário, tudo já está, de certa forma, pactuado no contrato. Uma empresa, ao avaliar novos investimentos em um determinado projeto considera todos os riscos que estão envolvidos, sejam eles políticos, econômicos, naturais ou legais. Ou seja, qualquer evento que poderia ser considerado imprevisível, está previsto no contrato. Sendo assim, não há que se falar em aplicabilidade da excessiva onerosidade superveniente aos contratos de derivativos.

Observa o autor ainda que a aplicação de teorias revisionistas aos derivativos ocasionaria "um verdadeiro colapso no mercado financeiro do país", sendo, segundo ele,

uma incrível fonte de risco legal e traria uma grande insegurança jurídica para o mercado de capitais brasileiro, fazendo com que a parte prejudicada, após graves perdas, sendo essas assumidas por ambas, possa discutir judicialmente o contrato, caso ocorram eventos que alterem os níveis de preços do mercado, perfeitamente possível nos dias atuais, como na recente crise do subprime americano. (ARRUDA, 2010, pp. 283-284).

Rafael Bianchini Abreu Paiva (2015, p. 109), em dissertação de Mestrado para a Faculdade de Direito da Universidade de São Paulo sobre os aspectos jurídicos dos derivativos, 
conclui pela inaplicabilidade das teorias revisionistas a estes contratos em razão de o diferencial de preços ser elemento ínsito ao negócio jurídico, constituindo o próprio objeto do contrato.

Fernando Gonçalves e Gustavo César de Souza Mourão, citados por Rafael B. A. Paiva (2015, p. 89), são assertivos em ponderar que os contratos derivativos não são passiveis de revisão judicial por onerosidade excessiva ou por imprevisão, entendendo que o evento futuro e incerto, bem como o risco, é intrínseco à natureza aleatória, constituindo objeto contratual.

Marco Aurélio Affonseca também defende que "o contrato de derivativo, classificado como contrato aleatório, não poderá ser rescindido por razão de dano ou de onerosidade excessiva" (SILVA; HIRATA, 2016, p. 169).

Para Eduardo Salomão Neto,

as partes que celebram as modalidades que chamamos de derivativos preveem a possibilidade de variações favoráveis ou contrárias a suas posições, sendo aliás esta a razão do negócio. Seria portanto inequitativo e contrário à lógica que pudessem se valer de tal escapatória. (SILVA; HIRATA, 2016, p. 169)

Pedro Darahem Mafud (2014, p. 91), também em obra produzida no programa de Mestrado da Faculdade de Direito da Universidade de São Paulo, observa ser inaplicável, em qualquer cenário, a teoria da imprevisão, uma vez que os derivativos possuem o risco como causa do pacto, de modo que "invocar a onerosidade excessiva por conta da consagração de tais riscos revela-se não apenas inoportuno, como também incoerente com a própria sistemática deste tipo contratual."

Para o autor, "as hipóteses de revisão, quaisquer que sejam [imprevisão, onerosidade excessiva, base objetiva do negócio] são incompatíveis aos derivativos, contrato por essência desequilibrado, cuja natureza, objeto e motivo negocial essencial é o próprio risco" (MAFUD, 2014, p. 92).

Judith Martins-Costa (2012, p. 28), em parecer sobre contratos de derivativos cambiais assinados entre instituições financeiras e empresas exportadoras, consignou entendimento pelo qual os derivativos são contratos aleatórios nos quais a álea atine justamente à variação cambial, sendo este o risco apreendido pela sua causa ou função econômica, integrando sua álea normal.

Fábio Ulhôa Coelho (2009, p. 89) igualmente recusa a aplicação da onerosidade excessiva aos contratos derivativos, suscitando que "o contrato de derivativo tem invariavelmente a natureza de investimento de alto risco" e que a revisão ou resolução do contrato seria "suprimir elemento essencial da alternativa escolhida, que é exatamente o elevadíssimo grau de risco assumido pelo investidor."

Por sua vez, em sentido contrário ao dos entendimentos colacionados, Raphael Andrade Silva e Alessandro Hirata (2016, p. 169) defendem que, se o evento que arrazoa a invocação da revisão contratual extrapola a álea normal do negócio, "caberá, em regra, a aplicação da teoria da imprevisão, pelo que não se pode concordar com a inadmissibilidade, de plano, de sua aplicação aos contratos aleatórios e, por conseguinte, aos derivativos."

Comentando julgados dos Tribunais de Justiça dos Estados de São Paulo, Santa Catarina e Espirito Santo, os autores concluem que

nenhuma das decisões encontradas na pesquisa jurisprudencial discutiu, com a profundidade necessária, a questão da aplicabilidade da teoria da imprevisão aos contratos aleatórios, não tendo sido encontrado nenhum debate de fôlego a respeito da conceituação de álea normal do negócio nem feita a distinção essencial entre risco interno e externo. Em síntese, ao limitarem a argumentação à ideia de que as partes que celebram contratos derivativos assumem riscos, nossos tribunais têm defendido indiretamente que, independentemente da natureza, extensão ou 
magnitude do risco, ele terá sido, de antemão, aceito pelos agentes econômicos (SILVA; HIRATA, 2016, p. 171).

Confirma esta posição retratada no comentário doutrinário acima, o entendimento prolatado no Recurso Especial $n^{\circ}$ 799.241, relatado pelo Ministro Raul Araújo e julgado pela Quarta Turma do Superior Tribunal de Justiça em 14 de agosto de 2.012:RECURSO ESPECIAL. CONSUMIDOR. RESPONSABILIDADE CIVIL. ADMINISTRADOR E GESTOR DE FUNDO DE INVESTIMENTO DERIVATIVO. DESVALORIZAÇÃO DO REAL. MUDANÇA DA POLÍTICA CAMBIAL. PREJUÍZO DO CONSUMIDOR. RISCO INERENTE AO PRODUTO. RECURSO PROVIDO. 1. Em regra, descabe indenização por danos materiais ou morais a aplicador em fundos derivativos, pois o alto risco é condição inerente aos investimentos nessas aplicações. Tanto é assim que são classificados no mercado financeiro como voltados para investidores experientes, de perfil agressivo, podendo o consumidor ganhar ou perder, sem nenhuma garantia de retorno do capital. Como é da lógica do mercado financeiro, quanto maior a possibilidade de lucro e rentabilidade de produto oferecido, maiores também os riscos envolvidos no investimento. 2. No caso em exame, o consumidor buscou aplicar recursos em fundo agressivo, objetivando ganhos muito maiores do que os de investimentos conservadores, sendo razoável entender-se que conhecia plenamente os altos riscos envolvidos em tais negócios especulativos, mormente quando se sabe que o perfil médio do consumidor brasileiro é o de aplicação em caderneta de poupança, de menor rentabilidade e maior segurança. 3. Não fica caracterizado defeito na prestação do serviço por parte do gestor de negócios, o qual, não obstante remunerado pelo investidor para providenciar as aplicações mais rentáveis, não assumiu obrigação de resultado, vinculando-se a lucro certo, mas obrigação de meio, de bem gerir o investimento, visando à tentativa de máxima obtenção de lucro. Não pode ser considerado defeituoso serviço que não garante resultado (ganho) financeiro ao consumidor. 4. Recurso especial conhecido e provido.

Paula Greco Bandeira (2011, pp. 119-120), em entendimento parecido, expõe que a oscilação dos parâmetros financeiros de referência, provocada pelo mercado, por ser normal, previsível, prevista, desejada pelas partes e ilimitada, obsta a invocação da excessiva onerosidade, mas, em se tratando de "eventos imprevisíveis, extraordinários e alheios aos contratantes, que não se relacionem à variação do parâmetro de referência, admite-se, tal como nos contratos aleatórios, a revisão ou resolução por excessiva onerosidade."

\subsection{A JURISPRUDÊNCIA PORTUGUESA}

A posição jurisprudencial discorrida neste tópico insere-se no contex to da crise financeira de 2008, a qual, originada do colapso do mercado de securitização do financiamento imobiliário nos Estados Unidos [crise do sub-prime], desembocou em uma crise econômica.

Deu-se, porém, inusitadamente, que o dólar estadunidense, ao invés de desvalorizar, como estava ocorrendo, recobrou sua valorização, de modo que, os derivativos referenciados na variação cambial "foram executados no sentido oposto às expectativas de boa parte de seus contraentes: quem esperava receber teve que pagar." (COELHO, 2009, p. 76).

Assim, a crise "veio suscitar uma apetência especial pela aplicação do instituto da alteração de circunstâncias" (CORDEIRO, 2017, p. 703), inclusive aos derivativos, in casu, o swap.

Swaps são trocas de ativos, de fluxos financeiros (MATTOS FILHO, 2015, p. 267), constituindo uma "troca de uma vantagem comparativa que um dos intervenientes detém num mercado financeiro, por um correspondente benefício que a outra parte possui noutro mercado" (PINTO, 1996, p. 49). 
Confirma o acórdão proferido pelo Superior Tribunal de Justiça da República Federativa do Brasil nos autos do Recurso Especial n 591.357, relatoria do Ministro Luiz Fux e julgado pela Primeira Turma em 24/05/2005 :

As operações de swap com cobertura hedge representam a aplicação de determinada quantia em moeda nacional em negócio cuja rentabilidade leva em conta uma moeda estrangeira, o que evita maiores prejuízos para a empresa contratante (hedger), que possua dívidas em moeda estrangeira, ficando sujeita à oscilação da referida moeda. Seu escopo original é servir para cobertura de riscos provenientes da taxa cambial flutuante, não obstante prestar-se também para a especulação financeira, desde que se aposte na elevação da moeda estrangeira cuja variação remunera aquele investimento e inexista passivo em tal moeda.

Por exemplo, caso uma empresa exportadora tenha assumido uma dívida corrigida pelos índices da inflação, ela poderá fazer um swap para vincular a correção da dívida à variação cambial do dólar.

Outro exemplo, caso a empresa possua uma dívida em dólar, para minimizar os riscos com a variação do dólar, cobrindo seu passivo em caso de valorização da moeda estadunidense, poderá realizar um swap de dólar por taxa de juros pré-fixada [CDB pré].

Desta maneira, na data de vencimento da dívida, o banco pagará à empresa a variação do dólar mais os mesmos juros da dívida que ela possui, e a empresa pagará ao banco uma taxa de juros pré-fixada, de modo que a empresa "ganhará" pela diferença entre o valor que receberá do banco e o que deverá repassar ao seu credor (FACCINI, 2017, p. 37 e pp. 40-42).

No contexto da crise financeira de 2008, o caso paradigmático do Supremo Tribunal de Justiça de Portugal, concernente à aplicabilidade da onerosidade excessiva aos contratos derivativos, teve por base uma relação de swap de taxa de juros.

No caso, uma autora celebrara com um banco a locação financeira imobiliária de um pavilhão industrial, e, na sequência, um swap para ficar a taxa de juro dentro dos limites de 4,55\%, caso a taxa ficasse entre $3,95 \%$ e $5,15 \%$, condicionando-se, porém, que, caso a taxa superasse $5,15 \%$ ou baixasse a menos de $3.95 \%$, haveria de se pagar a taxa superveniente (GONZALEZ; VENTURA, 2014, p. 63).

O responsável legal da autora, neste caso, possuía formação muito simples, nunca tendo contratado com bancos operações complexas (GONZALEZ; VENTURA, 2014, p. 64).

Sobreveio então que a crise financeira fez a taxa de juros cair drasticamente (GONZALEZ; VENTURA, 2014, p. 64), ensejando um prejuízo na casa de $€ 44.709,38$ (CORDEIRO, 2017, p. 715).

Judicializada a questão, deu-se procedência ao pedido da autora, o qual foi confirmado pela segunda instância, sob o argumento de que o desequilíbrio "foi extremamente agravado pela crise financeira, situação esta que não decorreu de um normal desenrolar da situação económica, entendendo a corte que a sua manutenção feriria os princípios da boa-fé que devem nortear a celebração dos contratos, e na qual as partes alicerçaram a decisão de contratar" (CORDEIRO, 2017, p. 715).

Interposto recurso ao Supremo Tribunal de Justiça, a corte ad quem consignou que ao momento da contratação, não havia possibilidade de prever a crise económica e financeira que se instalaria a partir de setembro de 2008 (GONZALEZ; VENTURA, 2014, pp. 68-69).

Seguiu o decisum legitimando a revisão ou resolução dos contratos derivativos "quando se verifique um profundo desequilíbrio do contrato, sendo intolerável com a boa-fé que o lesado o suporte." (GONZALEZ; VENTURA, 2014, p. 70).

Concluiu, pois, o Tribunal que, no caso concreto, era de se admitir a aplicação do remédio da alteração das circunstâncias, visto que houve "significativa descida das taxas de juro (que 
chegou abaixo dos 3,95\%), provocada por grave crise financeira, com grande divergência da taxa, superior, que as partes representaram como possível e a que o contrato pretendia assegurar (in casu, 5,15\%)" (GONZALEZ; VENTURA, 2014, pp. 70-71).

A decisão, então, configura posicionamento paradigmático, não sendo forçoso dizer que revolucionário, ao reconhecer a revisão ou a resolução de contratos derivativos por superveniência de crise econômica.

Como toda mudança substancial, não ficou imune a críticas (PAIVA, 2015, pp. 100-101). Pedro Gonzalez e João Ventura (2014, p. 79, pp. 82-83 e pp. 86-87), observam que

em termos meramente teóricos, a crise económica inserir-se-ia no escopo do instituto da alteração das circunstâncias, visto que se trataria de um evento imprevisível e anormal, plenamente exterior e causador de desequilíbrio na relação entre as partes. No entanto, importa discutir se, perante o caso analisado, se deve proceder a este mesmo raciocínio, na linha do que fez o douto Acórdão, algo que já nos parece bastante discutível.

[...]

Não tem sentido permitir a modificação ou a resolução de um contrato com base na alteração de circunstâncias quando o próprio contrato assume essa referida alteração como elemento essencial. Por outras palavras, se as partes tivessem previsto o sentido da alteração de circunstâncias seguramente não teriam sequer celebrado o contrato em causa, uma vez que é pressuposto essencial do mesmo a incerteza quanto às circunstâncias, em particular, quanto aos valores futuros das taxas de juro de referência. Sem incerteza ou perante a certeza de manutenção do estado de coisas - relativo às taxas de juro de referência - deixa de ter qualquer sentido a celebração de um contrato de swap de taxa de juro. Qualquer juízo de sindicância, no sentido de determinar até que ponto será tolerável a modificação nas taxas de juro de referência ou a partir de que momento seria aplicável a possibilidade de modificação ou resolução por alteração das circunstâncias, será arbitrário e por isso contrário aos fins da figura da alteração de circunstâncias. Sendo esta uma excepção ao princípio básico "pacta sunt servanda" não nos parece que a sua aplicação se compadeça com juízos puramente quantitativos. Concretizando, parece-nos que a aplicação da figura deve limitar-se aos casos em que não existe álea específica e a nos quais não se verifica esta inerente incerteza.

$[\ldots]$

um contrato de swap de taxa de juro, por via do qual as partes permutam taxas de juro diferentes com base em determinado valor nocional, é impermeável à alteração de circunstâncias que veio a causar uma descida acentuada das referidas taxas uma vez que tal está abrangida pelos riscos próprios do contrato. A álea, o risco específico de variação das taxas de juro é essencial e por isso inerente ao contrato de swap de taxa de juro e aos fins que lhe subjazem, pelo que necessariamente integra as circunstâncias em que as partes fundaram a decisão de contratar. Não pode por isso o risco ser excluído pela aplicação do regime de modificação ou resolução do contrato por alteração das circunstâncias. Qualquer limitação do risco por essa via seria sempre arbitrária e por isso contrária aos fins da figura da alteração das circunstâncias. - grifos nossos.

No entanto, a decisão da Relação de Guimarães que originou o recurso ao Supremo Tribunal de Justiça criticado acima, constitui supedâneo hígido a afastar a alegação de que, por ser o risco elemento ínsito aos derivativos, não haveria possibilidade de modulação a permitir a incidência da revisão ou resolução. 
Com efeito, para aquele tribunal, as obrigações a posteriori da crise no sistema financeiro atingiram oscilações para além do risco normal, de modo que o nível de alteração das circunstâncias foi tido como não coberto pelo risco próprio do contrato (CORDEIRO, 2017, p. 716).

A partir da doutrina de António Menezes Cordeiro (2017, p. 719) é possível, igualmente, extrair argumentação favorável a aplicação da teoria da revisão contratual ante os derivativos. Não obstante o autor citado seja de corrente contrária, pontua que "as partes negociaram justamente para distribuir, entre si, as possíveis variações."

A palavra-chave para a controvérsia, então, é o termo "possíveis". Não se descurando que a aplicação da revisão exige o nível de agravamento tenha "uma dimensão que supere quanto seja imaginável" (CORDEIRO, 2017, p. 719), denota-se, então, que, mesmo nos contratos derivativos, o risco assumido pelas partes é conjectural.

Neste sentido, o mercado de valores mobiliários está imbuído da obrigação de "divulgar toda a informação considerada relevante para a tomada de decisão do investidor, inclusive, os riscos inerentes ao investimento pretendido" (FERREIRA, 2016, p. 4).

Isso vale dizer, portanto, que os riscos assumidos pelas partes se submetem às circunstâncias - e seus respectivos níveis e percentuais - disponíveis e ponderáveis à época da contratação:

O dever de informação incide tanto sobre as condições efectivas como as passíveis de se observarem, atendendo que existem os riscos inerentes ao mercado. (...) Revela-se igualmente muito importante que a informação a ser prestada incorpore todos os elementos relevantes, do próprio intermediário; dos serviços que presta e dos que subcontrata; dos instrumentos financeiros sobre os quais se vai reflectir a sua prestação; dos riscos e dos custos do serviço prestado. É importante frisar, que a informação deverá ser completa, verdadeira, actual, clara, objectiva e lícita, permitindo que a decisão do investidor seja, esclarecida e fundamentada (FERREIRA, 2016, p. 5).

O dever de informação surge, com efeito, em decorrência das relações de confiança, transparência e lealdade entre todos os participantes do mercado de capitais. De fato, o mercado de capitais altera-se conforme o tratamento dispensado às informações, as quais "podem ter potencial capacidade de influir sobre o processo da livre oferta e demanda de valores mobiliários" (BITENCOURT; BREDA, 2014, p. 403).

Desta sorte, o dever de informação obsta que os investidores corram o risco de sofrerem diminuição de seu patrimônio em virtude de operarem em desvantagem de conhecimento e concretiza a regra mais básica da negociação de valores mobiliários: a igual divisão do risco entre todos (BITENCOURT; BREDA, 2014, p. 403).

Apesar deste direito dos investidores e dever dos agentes envolvidos com o sistema financeiro de mercado de capitais e valores mobiliários, os pequenos investidores "tendem especialmente a ter os direitos de informar, de se informar e de ser informado mitigados diante do plano essencialmente financeirizado do mercado" (ALVES, 2014, p. 3).

Assim, quando se fala que a contratação no mercado de capitais é conjectural, está a se falar que a decisão dos contratantes se pautou pela completude, veracidade, actualidade, clareza, objectividade e licitude da informação a respeito dos eventuais ganhos e, sobretudo, das possibilidades de perdas (FERREIRA, 2016, p. 6).

Neste contexto de informações a serem prestadas,

tratando-se de obrigações de taxa variável, há necessidade também de que a informação a ter em conta, incluam outros factores que não só o financeiro, nomeadamente de toda envolvente económica que de alguma forma acabará por 
influenciar a variação da própria taxa de juro e consequentemente o preço das obrigações (FERREIRA, 2016, p. 12).

Assim, no âmbito judicial, a revisão estará autorizada quando os fatos supervenientes e os níveis de gravame alcançados superem a envolvente econômica disponibilizada ao contratante quando da conclusão do pacto:

as relações econômico-financeiras passaram a conceber o mercado não apenas como facilitador das situações de troca, mas também enquanto facilitador de resultados distributivos. Em vez de um acordo irrevogável, estático e intangível, tem-se hoje um instrumento tendente à dinamicidade da economia, à flexibilidade da estrutura negocial e a determinados fatores reais de poder (ALVES, 2014, p. $5)$.

Outra não poderia ser a interpretação, considerando-se a eficácia horizontal e vertical dos direitos humanos fundamentais:

os direitos fundamentais não devem ser encarados apenas como direitos de defesa contra interferências ilegítimas do Poder Público, mas tratados como princípios objetivos, legitimadores da ideia de que o Estado também se obriga a garanti-los contra agressões propiciadas por terceiros. (...) são, portanto, alçados a instrumentos reais de efetividade e eficácia da dignidade, da justiça e da solidariedade contratuais entre obrigações gerais e específicas de informação adequada ao investidor-consumidor do mercado financeiro (ALVES, 2014, p. 3).

A eficácia dos direitos fundamentais às relações financistas se demonstra tanto mais necessária haja vista que "a vulnerabilidade do investidor se mostra cada vez mais latente não só no que diz respeito à instituição, mas também no que tange à própria lógica irracional do mercado" (ALVES, 2014, p. 5):

A ideia de um mercado eficiente, com preços que correspondem à escorreita carga de informação disponível para os agentes, não passa de uma conjectura sem aproximação com as finanças comportamentais. [...] os agentes econômicos têm racionalidade limitada nas decisões financeiras, pressupondo que os mercados não emanam informações suficientes para a determinação de todos os eventos futuros (ALVES, 2014, p. 4).

Desta sorte, assumir os contratos derivativos inaptos à incidência da revisão ou resolução por excessiva onerosidade é, a uma, considerar um mercado completamente racional que atinge as perspectivas conjecturais, e a duas, admitir que os investidores, imbuídos de espirito ganancioso, admitem perdas de qualquer monta, sujeitando-se a um jogo de perda total, inclusive que atinja o mínimo existencial nuclear da dignidade humana.

Quanto ao primeiro aspecto, o fato da irracionalidade do mercado é elemento justificante da constitucionalização do direito privado, conforme corrobora Daniel Sarmento:

A sociedade brasileira é profundamente injusta, e as relações privadas que nela se travam são permeadas pela assimetria e opressão. A violação dos direitos humanos, neste quadro, não provém apenas do Estado e dos seus agentes, mas de múltiplos atores, presentes em cenários variados como a família, a empresa, o mercado e a sociedade civil (IRIBURE JUNIOR; GUIMARÃES, 2017, p. 131).

Assim, é preciso equacionar os riscos e a lógica dos contratos do mercado de capitais com direitos fundamentais. Não se trata de desconsiderar a liberdade individual, mas sim de assegurar 
eficácia dos direitos fundamentais diretamente nas relações privadas (IRIBURE JUNIOR; GUIMARÃES, 2017, p. 132).

No que concerne ao segundo aspecto, de se legitimar a assunção de riscos desmedidos, não é forçoso lembrar que, mesmo a atividade empresarial sendo sujeita a riscos tais quais os existentes no mercado de capitais - e bem cabe frisar que o mercado societário se interliga com o mercado de valores mobiliários - a limitação da responsabilidade dos sócios nas sociedades limitadas decorre justamente do fato de que "o direito deve estabelecer mecanismos de limitação de perdas" (COELHO, 2017, p. 178), demonstrando assim, que há uma funcionalização da atuação do mercado em razão de valores e princípios maiores, constitucionalmente assegurados (SAMPAIO; FERREIRA, 2014, p. 169).

Estas perdas, destaque-se, devem ser compreendidas a luz de "novos parâmetros, com base na verificação dos desequilíbrios modernos e com base nas necessidades contemporâneas" (SAMPAIO; FERREIRA, 2014, p. 154), postulado este que se coaduna com a diretriz traçada para a aplicação da revisão ou resolução aos derivativos: a natureza intrínseca do risco não mais se habilita a obstar - de per si e aprioristicamente - a intervenção judicial nos derivativos, em razão de as perdas subjacentes deverem ser verificadas a luz desses novos parâmetros:

(...) a função social é um instrumento adotado pela hermenêutica advinda da racionalidade do direito civil-constitucional, que importa na releitura de todas as figuras jurídicas à luz de seu conteúdo solidarista. Mesmo a figura jurídica mais privatística ganha outro conteúdo quando aplicado sob a ótica dos preceitos constitucionais. (SAMPAIO; FERREIRA, 2014, p. 169)

O contrato contemporâneo, incluídos os derivativos, exerce papel de ponto de encontro de direitos fundamentais (SAMPARIO; FERREIRA, 2014, p. 155), "materializando um vertente de eficácia do princípio da dignidade da pessoa humana” (SAMPAIO; FERREIRA, 2014, p. 161, sic).

Por fim, é preciso reconhecer que, com a constitucionalização do Direito, o direito civil, rectius, todo o direito privado, deixou de ser um estatuto de relações patrimoniais (RECKSIEGEL; FABRO, 2015, P. 170). Assim, a inaplicabilidade da revisão contratual aos contratos de derivativos representa a primazia do patrimonial sobre o respeito à dignidade pessoal do investidor, configura patente retrocesso à eficácia dos direitos humanos fundamentais às relações privadas.

\section{CONCLUSÃO}

Conforme discutido, à luz da eficácia horizontal dos direitos humanos, cuja incidência transcende a relação Estado-particular, mas atinge as trocas intersubjetivas privadas, o mercado financeiro deixou de ser focado no pensamento liberal clássico de justiça comutativa e igualdade apenas formal, denotando ações afirmativas de lealdade, igualdade substantiva e justiça distributiva, dentre as quais pode se incluir a aplicabilidade da revisão ou resolução contratual dos derivativos.

Considerando que os mercados de capitais, ações e valores mobiliários, bem como, por extensão, contratações do sistema financeiro, são circunstanciais, desenvolvendo-se a partir de um complexo de informações sobre a conjectura subjacente aos elementos do contrato discutido, e somado ao fato de que não raro a realidade subsequente não corresponde à envolvente econômica prevista quando da conclusão do contrato, mormente no que tange aos níveis das variações envolvidas, a intangibilidade do contrato feriria de morte o princípio da dignidade humana, ao chancelar a ruína pessoal, e a própria eficácia dos direitos humanos, enquanto proibição de excesso.

Em síntese, por mais que os derivativos envolvam assunção de riscos pelas partes, essa assunção não permite admitir que as partes assumiram quaisquer riscos, e riscos em quaisquer níveis. Isso decorre efetivamente da eficácia dos direitos humanos solidificada no direito privado pelo movimento constitucionalista que prestigiou a dignidade humana sobre o afã patrimonial, 
estabelecendo padrões que limitam o exercício de posições jurídicas, tais como os institutos do abuso de direito, a proibição de excesso e a limitação de perdas.

De certo, porém, a conclusão que se solidifica é a de que estes contratos derivativos só devem ser praticados por especialistas, entre si, não se admitindo a propositura para qualquer perfil de aderente, contratos arriscados e complexos, como são swaps e não raro, todo o mercado de capitais e valores mobiliários.

\section{REFERÊNCIAS}

ALVES, André Gomes de Sousa. A proteção jurídica do investidor-consumidor do mercado financeiro e o (re)equilíbrio do conflito de interesses na relação principal-agent. Disponível em: http://www.publicadireito.com.br/artigos/?cod=ba01baa4856d494a. Acesso 23 mar. 2018

ARRUDA, Daniel Sivieri. Os contratos de derivativos e a inaplicabilidade da revisão ou resolução por excessiva onerosidade. Disponível em: http://bibliotecadigital.fgv.br/dspace/bitstream/handle/10438/10307/Cole\%C3\%A7\%C3\%A3o\%2 0Jovem\%20Jurista\%20\%202010.pdf? sequence=1\&isAllowed=y\#page=267. Acesso em 19 mar. 2018.

BANDEIRA, Paula Greco. Os contratos de derivativos e a teoria da imprevisão. Revista dos Tribunais: RT, v. 100, n. 904, fev. 2011.

BITENCOURT, Cezar Roberto; BREDA, Juliano. Crimes contra o sistema financeiro nacional e contra o mercado de capitais. $3^{\mathrm{a}}$ ed. São Paulo: Saraiva, 2014.

BRASIL. Superior Tribunal de Justiça. Recurso Especial nº 591.357. Rel. Min. Luiz Fux. Primeira Turma. Data de Julgamento: 24/05/2005.

BRASIL. Superior Tribunal de Justiça. Recurso Especial no 799.241. Rel. Min. Raul Araújo. Quarta Turma. Data de Julgamento: 14/08/2012.

BRASIL. SÃO PAULO. Tribunal de Justiça. Apelação nº 0105673-27.2010.8.26.0100, rel. Francisco Loureiro, $37^{\mathrm{a}}$ Câmara de Direito Privado, j. 24.11.2011.

BRASIL. SÃO PAULO. Tribunal de Justiça. Apelação nº 0002926-57.2015.8.26.0218, rel. Kioitsi Chicuta, 32a Câmara de Direito Privado, j. 10.08.2017.

CARDOSO, Luiz Philipe Tavares de Azevedo. A onerosidade excessiva no direito civil brasileiro. Dissertação (Mestrado em Direito). Faculdade de Direito da Universidade de São Paulo. São Paulo, 2010.

CLIMENI, Luiz Alberto Orsi; KIMURA, Herbert. Derivativos financeiros e seus riscos. São Paulo: Atlas, 2008.

COELHO, Fabio Ulhôa. Os derivativos e a desvalorização do Real em 2008. Revista de Direito Bancário e do Mercado de Capitais: RDB, v. 12, n. 44, abr./jun. 2009.

COELHO, Fabio Ulhôa. Novo manual de direito comercial: direito de empresa. 29a ed. São Paulo: Revista dos Tribunais, 2017. 
CORDEIRO, António Menezes. Tratado de Direito Civil. Tomo IX: Direito das obrigações cumprimento e não-cumprimento, transmissão, modificação e extinção. $3^{\mathrm{a}}$ ed. Coimbra: Almedina, 2017.

CUNHA, Wladimir Alcibíades Marinho Falcão. Revisão judicial dos contratos: do Código de Defesa do Consumidor ao Código Civil de 2002. São Paulo: Método, 2007.

CURY, Maria Fernanda Calado de Aguiar Ribeiro. Onerosidade excessiva em acordo de acionistas. Dissertação (Mestrado em Direito). Faculdade de Direito da Universidade de São Paulo. São Paulo, 2014.

DIAS, Antônio Pedro Medeiros. Revisão e resolução do contrato por excessiva onerosidade. Belo Horizonte: Fórum, 2017.

DINIZ, Maria Helena. Curso de direito civil brasileiro. Vol. 3: Teoria das obrigações contratuais e extracontratuais. 30ª ed. São Paulo: Saraiva, 2014.

FACCINI, Leonardo. Desvendando os derivativos - II: opções, swaps e taxas. Superintendência de Relações com Empresas da Comissão de Valores Mobiliários. 31 ago. 2017. 59 slides.

Disponível em:

http://www.portaldoinvestidor.gov.br/portaldoinvestidor/export/sites/portaldoinvestidor/menu/ati vidades/CentroEducacional/Apresentacoes/Apresentacoes2017/2017-08-31-

DesvendandoosDerivativos2-LeonardoFaccini.pdf. Acesso em 20 mar. 2018.

FERREIRA, Carla. A importância do dever de informação no mercado dos valores mobiliários. Departamento de Comunicação e Apoio ao Investidor da Comissão do Mercado de Capitais da República de Angola. Disponível em: http://www.cmc.gv.ao/sites/main/pt/Lists/CMC\%20\%20PublicaesFicheiros/Attachments/1025/A $\% 20 \mathrm{imp} \% \mathrm{C} 3 \%$ B4rtancia\%20do\%20dever\%20de\%20informa\%C3\%A7\%C3\%A3o\%20no\%20m ercado\%20dos\%20valores\%20mobili\%C3\%A1rios.pdf. Acesso 22 mar. 2018.

GONZALEZ, Pedro; VENTURA, João. Contrato de swap e alteração de circunstâncias anotação ao acórdão do Supremo Tribunal de Justiça, processo nº 1387/11.5TBBCL.G1.S1. In: Cadernos do Mercado de Valores Mobiliários, n48, ago. 2014. Disponível em: http://www.cmvm.pt/pt/EstatisticasEstudosEPublicacoes/CadernosDoMercadoDeValoresMobilia rios/Documents/Cadernos48Anotacao.pdf. Acesso em 20 mar. 2018.

GONÇALVES, Carlos Roberto. Direito Civil Brasileiro. Vol. 3: Contratos e atos unilaterais. $11^{\mathrm{a}}$ ed. São Paulo: Saraiva, 2014.

HULL, John C. Options, futures \& other derivatives. 5a ed. New Jersey: Prentice Hall, 2003.

IRIBURE JÚNIOR, Hamilton da Cunha; GUIMARÃES, Henrique Cassalho. O ORDENAMENTO JURÍDICO NO CONSTITUCIONALISMO BRASILEIRO: PERPLEXIDADES CONCERNENTES AO DIREITO CIVIL. Revista de Direito Brasileira, [S.1.], v. 17, n. 7, p. 125-140, ago. 2017. ISSN 2358-1352. Disponível em: <http://indexlaw.org/index.php/rdb/article/view/3047/2786>. Acesso em: 13 abr. 2018. 
MAFUD, Pedro Darahem. Racionalidade econômica e aspectos jurídicos dos derivativos: uma análise jurisprudencial. Dissertação (Mestrado em Direito). Faculdade de Direito da Universidade de São Paulo. São Paulo, 2014.

MARTINS-COSTA, Judith. Contratos de derivativos cambiais. Contratos aleatórios. Abuso de direito e abusividade contratual. Boa fé objetiva. Dever de informar e ônus de se informar. Teoria da imprevisão. Excessiva onerosidade superveniente. [Parecer]. Disponível em: https://docs.wixstatic.com/ugd/451585_6afd800dc0d8455794f4eedf3b71844a.pdf. Acesso 14 mar. 2018.

MATTOS FILHO, Ary Oswaldo. Direito dos valores mobiliários. Vol. 1. Tomo 2. São Paulo: FGV, 2015.

PAIVA, Rafael Bianchini Abreu. Natureza jurídica, regulação e tutela dos instrumentos derivativos. Dissertação (Mestrado em Direito). Faculdade de Direito da Universidade de São Paulo. São Paulo, 2015.

PINTO, António Mendes. Os produtos de gestão do risco financeiro no financiamento empresarial - as práticas financeiras das empresas da Beira Interior. Dissertação (Mestrado em Gestão). Universidade da Beira Interior. Covilhã, 1996.

PONTES DE MIRANDA, Francisco Cavalcante. Tratado de Direito Privado. Tomo III: negócios jurídicos, representação, conteúdo, forma, prova. Atualizado por Vilson Rodrigues Alves. $2^{\mathrm{a}}$ ed. Campinas: Bookseller, 2001.

RECKZIEGEL, Janaína; FABRO, Roni Edson. Autonomia da Vontade e Autonomia Privada no Sistema Jurídico Brasileiro.Revista de Direito Brasileira, [S.1.], v. 8, n. 4, p. 161-177, ago. 2015. ISSN 2358-1352. Disponível em: <http://indexlaw.org/index.php/rdb/article/view/2888>. Acesso em: 13 abr. 2018.

RIO GRANDE DO SUL. Tribunal de Justiça. Apelação nº 70020068730, rel. Iris Helena Medeiros Nogueira, 9 $9^{\mathrm{a}}$ Câmara Cível, j. 08.08.2007.

ROPPO, Enzo. O contrato. Coimbra: Almedina, 2009.

SAMPAIO, Marcelo de Souza; FERREIRA, Leonardo Sanches. Solidarismo Ético e Liberdade Negocial: A Livre Iniciativa a partir da Constituição de 1988. Revista de Direito Brasileira, [S.1.], v. 7, n. 4, p. 149-171, jun. 2014. ISSN 2358-1352. Disponível em: <http://indexlaw.org/index.php/rdb/article/view/2789/2658>. Acesso em: 13 abr. 2018.

SANTOS, Rafael Gaspar. A inaplicabilidade da teoria da imprevisão aos contratos de derivativos. Monografia [LLM de Direito dos Mercados Financeiro e de Capitais e LLM de Direito dos Contratos] INSPER - Instituto de Ensino e Pesquisa. São Paulo, 2017.

SILVA, Plinio Marcos de Sousa. Mercado de Capitais: sistema protetivo dos interesses coletivos dos investidores e consumidores. Dissertação (Mestrado em Direito). Universidade de Ribeirão Preto. Ribeirão Preto, 2008. 
SILVA, Raphael Andrade; HIRATA, Alessandro. Contratos derivativos: regime e efeitos jurídicos. Disponível em:

https://www.conpedi.org.br/publicacoes/9105o6b2/ujz5v2j4/6L4D0RrX9B2HV4q8.pdf. Acesso 19 mar. 2018. 